\title{
Investigation on the Applicability of Reggio Emilia Approach in Teaching Early Childhood Education: An Intensive Comparison between China and Tanzania
}

\author{
Sarah Vincent Chiwamba ${ }^{1}$ \\ ${ }^{1}$ Department of Education, Sokoine University of Agriculture, Morogoro, Tanzania \\ Correspondence: Sarah Vincent Chiwamba, Department of Education, Sokoine University of Agriculture, P.O. \\ Box 3038, Chuo Kikuu, Morogoro, Tanzania. E-mail: edmund_sarah@yahoo.com
}

Received: March 31, 2016

Accepted: April 28, 2016

Online Published: July 7, 2016

doi:10.5539/jedp.v6n2p29

URL: http://dx.doi.org/10.5539/jedp.v6n2p29

\begin{abstract}
There have been rapid economic and social demands that have continued to challenge the traditional teacher, child and parent interactions in early child education programs. Many developed countries have strategized several approaches to counter these challenges. However, third world countries are still formulating policies which can be sustainable in their present economic statuses. The Reggio Emilia (RE) Early Childhood Education (ECE) approaches has been instrumental in increasing the levels of interactions between teacher, child and the parent in developed countries. Nevertheless, a more dynamic and comprehensive approach is needed to cater for the economic and multiethnic social needs of early childhood education in developing countries. This study investigated the level of teacher, child and parent interaction in China and Tanzania with the aim of establishing the workability of Reggio Emilia (RE) in these two diverse countries. Carefully designed questionnaires based on the core values of Reggio Emilia approach has been used to obtain data from a sample of 60 early childhood teachers from China and 60 early child hood teachers from Tanzania making total of 120 early childhood teachers. Both private and public early childhood schools of China and Tanzania were involved in this study whereby from China a total of 8 schools were involved and Tanzania a total of 12 schools were involved. Both quantitative and qualitative design has been employed in this study with the use of questionnaire and interview methods in data collection from the field while social statistical software (SPSS 15) and Origin 7.0 has been used to analyze data and making of charts and graphs for visualization of the results. Result obtained from this study revealed that, Reggio Emilia interactive approach was applicable and welcomed by significant number of teachers and policy approaches; However on the other side, the findings revealed poor relationship between parents and the role of emergent curriculum to its fully meaning was not well fulfilled as most of early childhood schools in China and Tanzania found to practising the whole class teaching where by teacher knows everything. It was concluded that, the way children's are being taught in one country will be totally different from another country although the basic outcome of the learners should be similar. The important aspect to put into consideration is people's culture, environment, and their economic status accordingly. Hence there is a need for both countries of study to review their early childhood education policies in order to create better learning opportunities for all children.
\end{abstract}

Keywords: Early Childhood Education, Reggio Emilia approach, China, Tanzania

\section{Introduction}

There have been alignments of diverse curriculum approaches with the increasingly open and diversified society. Some of the widely adopted and localized curricula are the Reggio Emilia (RE) and Montessori (Li, H., \& Li, P., 2003; Zhu \& Zhang, 2008). All approaches have an aspect of parental involvement although when a child starts going to school, there is less parent involvement in the day to day learning. Hence appropriate approaches are necessary to introduce a child to this learning environment and lay a foundation which a child can be able to overcome the "transitions shocks" (Malaguzzi, 1996). In China, the document called The Rules on Kindergarten Routines, issued by the National Education Committee of 1989, reflected the early childhood education reforms so as to enable environment for a child to be able to face the world, the future and modernization. One of the aspects emphasized was an integrated curriculum. This creative and adaptive curriculum learning approach was 
supposed to provide a framework for high-quality subject interaction during early childhood teaching and learning process.

The interactive educational approaches to Early Childhood Education (ECE) can help to create a very rich environment for the child learning. These interactive approaches intermingle between teacher, child and parents. Such kind of interactions can be influenced greatly by the nature of a school curriculum adopted. However, the popular RE approach emphasizes an emergent curriculum and not a planned curriculum. In the RE approach the teacher's role as facilitator requires him to provide students with relevant resources for learning, including but not limited to pedagogy, projects ideas, practical strategies, documentation and even co-construction. Edwards and Kutaka (2015) argued that, the familiar role of the teacher as "program planner" in Reggio Emilia may change to be a creator of the environment so long as teachers are responsible to provide quality program by preparing the space and environment, indoors and out, the quality and aesthetics of materials, furnishings, and images in which their "taste" or "flavor" usually helps child appreciate, love, respect, and take advantage of the environment.

The teacher is ever-aware that in designing the spatial organization, initial learning materials, and potential topics for exploration, he is not necessarily structuring a curriculum that must be stuck on to rather, the curriculum, which encompasses all the mentioned components among others, will be further developed according to the school session. The learner's interests in particular topics, their response to the immediate and external environments and their competency in introduced skills, as well child-child and child-teacher interaction help to shape the activities that make up in internalizing the curriculum. Moreover, studies have shown that children benefit when parents and the early childhood educators share a common commitment for the mental development of the learners. Virtually all successful programs have parent education and parent involvement components, and nearly all investigators cite these as critical to program success. Cotton and Green's (1988) review of the parent involvement research revealed the powerful effects of such involvement on children's learning.

\section{Methodology}

The study was conducted in China and Tanzania early childhood schools using a representative sample of 120 early childhood teachers from both public and private early childhood schools. The totals of 20 early childhood schools were included in this study from both China and Tanzania. From each school, the total of 5-10 early childhood teachers responded to the questionnaire making total of 120 early childhood teachers including the heads of Schools. The researcher did not put into consideration about gender, however most of the respondents were female Teachers as most of the early Childhood Schools in both countries of study seems to have more female teachers compared to male teachers. In other Early Childhood Schools did not have even a single male teacher.

Quantitative research design with the use of questionnaires which was developed by the researcher based on the core values of Reggio Emilia approach. Some aspects of qualitative design through documentary review involving perusing school reports on teachers training policies and school documentation of children's activities and interview was also conducted on information supplied by the head teachers in the early childhood schools. This simultaneous triangulation of quantitative and qualitative methods is thought to be relevant in cross-checking, confirming and cross validating finding within a single study (Cresswell, 2003). The social statistical software (SPSS) and Origin 7.0 was used in analyzing and graphical visualization of the results. The results of this study show a good representation of the learning environment in both China and Tanzania because of the fair uniformity of the early child education structures alongside the respective social and cultural contexts of the preschools.

\section{Findings}

\subsection{Child-Teacher Relationship}

The results showed that both countries have cordial close relationships that exist between the children and their teachers with a $76.7 \%$ and $90.0 \%$ interaction satisfaction in China and Tanzania respectively. Encouragingly, none of early childhood teachers from China responded to be dissatisfied; however there were $10.0 \%$ of the teachers in Tanzania who indicated some dissatisfaction in their current relationship with the children. Other details of the dissatisfaction levels are shown in Figure 1. 


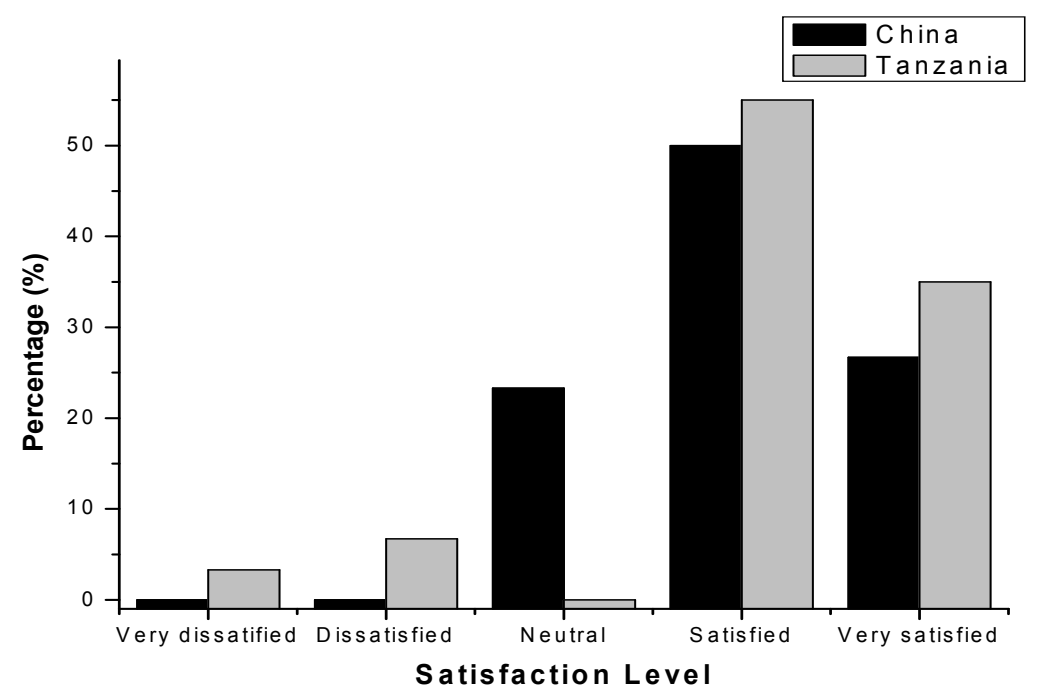

Figure1. Satisfaction level of early childhood teachers on child-teachers interactions for both China and Tanzania

\subsection{Parents-Child Interactions}

Result shows that early childhood teachers from both countries of China and Tanzania were highly satisfied with the way parents involve themselves on their child's learning. The results indicates that $71.7 \%$ of early childhood teachers from Tanzania seemed to be on the side of satisfaction level and about $23.3 \%$ seemed to be on the side of dissatisfaction. On the side of China about $66.6 \%$ of early childhood teachers were satisfied with parents involvement on their child's learning and only $5.0 \%$ responded that were not satisfied with parents involvement on their child's learning as indicated on Figure 2.

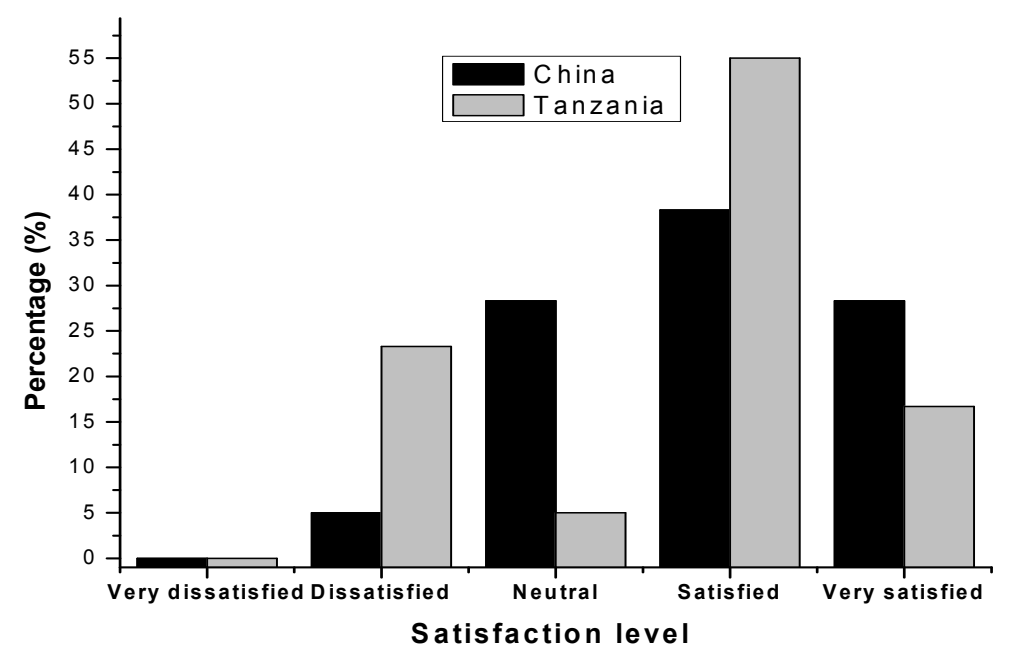

Figure 2. Satisfaction level of early childhood teachers on the parents-child interactions for both China and Tanzania

Tanzanian early childhood schools had $45.0 \%$ of early childhood teachers responding that they were satisfied with parent's response to their children's homework while $36.7 \%$ of early childhood teachers were not satisfied with the parent's response to their Child's home work. In China however, only $3.3 \%$ of early childhood teachers seemed to be dissatisfied with parent's response to their child's home work (Figure 3). This is comparatively very low percentage as compared to that of Tanzania (36.7\%). However, majority of the early childhood teachers in China were satisfied with the parent's response to their children's homework (68.4\%) as shown in Figure 3. 


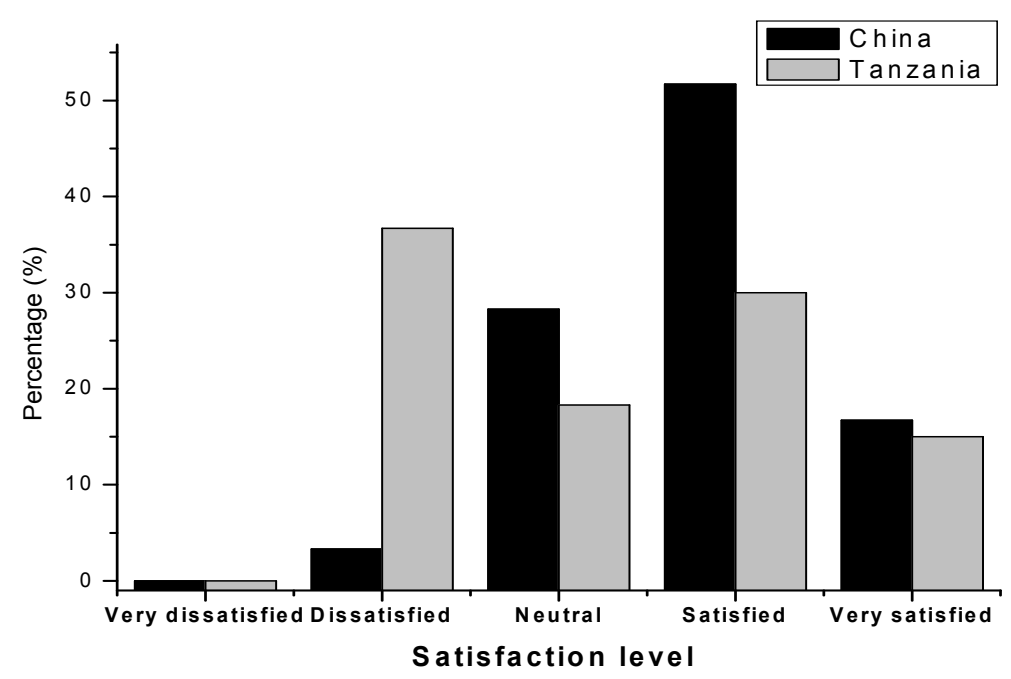

Figure 3. Satisfaction levels of early childhood teachers on parents' response to their children's homework in both China and Tanzania

\subsection{Teacher-Parent Interactions}

About $75.0 \%$ of Chinese early child teachers responded that they were satisfied with how their schools provided feed back to the parents about their children's progress. The same trend was observed amongst the Tanzanian teachers which had $86.7 \%$ recording satisfaction although a higher percentage showed dissatisfaction $(5 \%)$ compared to China's (3.4\%) as shown in Figure 4.

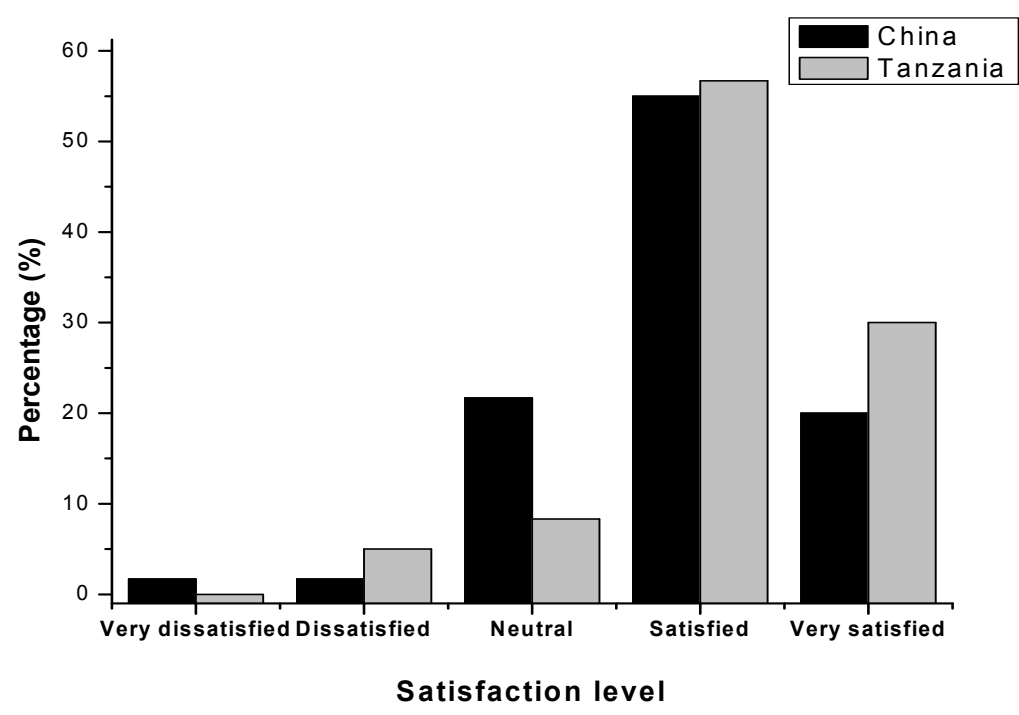

Figure 4. Satisfaction levels of early childhood teachers on the school feedback to parents from both China and Tanzania early childhood schools 


\section{Discussions}

There are several curriculum and pedagogical models that have recently been introduced to China. These are for example the Montessori curriculum, the Project Approach, High/Scope, Reggio Emilia, Developmental Appropriate Practice (DAP) and the Whole Language Approach. Early child educators have tried to adopt some of these models, but some of them have failed to function in the Chinese educational environment ( $\mathrm{Li}, \mathrm{H} ., \& \mathrm{Li}$, P., 2003). On the other hand many third world countries like Tanzania are much poorer than China and might have a higher challenge to introduce a western early childhood education approach. However, there are efforts to help introduce such systems in many poor countries. This must be done with regard to the multicultural and modernistic influences in these countries (Tobin, 2007).

\subsection{Interactive Approaches}

Although early childhood curriculum reforms in China and other third world countries are undergoing reforms and that there are differences between different groups in different areas, there is need to develop different curricula for each of them (Zhu, 2004). However, there is equally a need to seek strategies to minimize these differences in order to achieve the proposed common global goals. Economic changes and trends are making some early childhood teachers to complain that teachers who could teach well in the past are now being rendered as those who are incapable by mainly the electronic media. However an analysis of the various interactive pathways enables one to perceive the loop holes which could be the main causes of such situations. Early researchers show that China had perceived such involvement mainly through the establishment of a development index system to help parents and caregivers to "improve scientific care and education for young children" (Zhu, 2002). This in a way justified the high percentage of parent-teacher interaction in China compared to that in Tanzania.

\subsection{Development of ECE Programs in China and Tanzania}

The three cultural threads that profoundly shaped the different aspects of early childhood education in China are the traditional culture, communist culture and the western culture (Wang \& Spodek, 2000; Zhu \& Wang, 2005). This include views a young child's view of learning and views of the appropriate teacher-child relationships. Studies have shown that the Chinese people are more group-oriented than individual-oriented. They are more extrinsically motivated as opposed to intrinsically motivated people who tend to value drilling, memorizing and discipline rather than creativity and freedom (Chan, 1996; Cheng, 1996).

Result based on the study conducted between China and Tanzania revealed that many $3^{\text {rd }}$ world countries are much poorer to stand up the pressure of introducing western approach to early childhood education. The findings from research showed that there is weakness on the collaboration between parents to parents in early childhood education which is amongst the key features in RE approach on teaching early childhood education. RE emphasizes much on the reciprocal relationship between teachers, child and parents as both of them are the key stakeholders in the learning of the children. Although results showed that there is parental involvement in day to day activities on early childhood but still there is weakness in relationship existing among parents. Most of the parents came together through early childhood school meetings otherwise there is no specific program for them to discuss together about the performance of their child in schools and getting to know each other

Massive literature on parent-pre-school relationships in Tanzania has concentrated on parental influence on curricula decisions and implementation. For example, Kissassi (1994), Mbise (1996) and Chowan (1991) reported that parents in Tanzania pressurize teachers to provide literacy and numeracy skills to preschoolers. A preschool which fails to make a child to read, write and count is therefore considered useless. However, their literature did not show how parents were made to participate in their children's education under the auspicious of preschools.

\subsection{Parent-Parent Interactions}

Ratelle et al. (2005) defined parental involvement as providing resources to a child in the form of spending time with the child, being interested and attentive to the child, as well as providing emotional support. In addition to that Smith et al. (2013) argued that Parent engagement in children's education is not only increasingly viewed as an essential support to children's learning in early care and education programs but also is very essential throughout the school years. This study found that the level of participation in Chinese early childhood schools is of high status. Large number of early childhood teachers (68.4\%) responded that they were satisfied with parental involvement on their children's school activities especially making a follow up of their children's homework. While Tanzania shows little participation of parents response to their children's homework only 
$45.0 \%$ of early childhood teachers responded that they were satisfied. Tanzanian early childhood schools still have a big challenge of maintaining the participation of parents in the early childhood education this could be done through educating parents about how important they are in their children's learning. Parents in China take more responsibility on their children's school activities. From an interview conducted with some heads of the early childhood schools from China we found out that, they normally conduct activities like workshops which enable teachers and parents come together and discuss different issues concerning children such as health habits in young children. On the other hand, there is positive child-teacher relationship existing among early childhood schools in both countries. From China (76.7\%) of early childhood teachers were satisfied and Tanzania (90.0\%). This shows that teachers maintain good relationship with children in early childhood schools of both China and Tanzania.

Zhu (2009) and Joanne Vaughan (1991) argued that, one child policy in China has had an effect on the early childhood education by for example strengthening the emphasis of education on young children and a family strong involvement and investment. In the case of Tanzania, parents find themselves in a difficult situation to make follow up of their children's learning due to the influence of extended families, cultural differences and economical statuses (Birgen, 2008). Parents do not have enough time to make follow up of their children's learning. The situation is more complicated due to lack of established policies in Early Childhood Education (ECE) before 2004 and is still not a major priority in the Tanzania Development vision of 2025 (Mtahabwa, 2007). This clearly shows how some third world government view preschool education by treating and positioning it on the "back-seat position" mainly because of not realizing that "the costs of intervening in ECE can be immediate and high, but the investment is long-term rewarding" (Doryan et al., 2002).

The state in Tanzania preschools is mainly like the one in the rural China where parents are largely unaware of the early intervention in ECE which can enhance children's intelligence and social skills. Such parents mainly concentrate their efforts in providing clothing and food making the child-child interaction among Chinese early childhood in the rural to be lower compared to the situation in urban areas (Xie et al., 1999).

Henderson et al. (1994) states that when schools work together with families to support learning, children tend to succeed not just in schools but throughout their life. In fact student achievement in schools is not income or social status, but depends on the extent to which that student's family is able to create a home environment that encourages learning and to what extent parents become involved in their children's education at school and in the community. Nevertheless the findings revealed that most of the parents in third world countries lack skills to support their children with school activities.

\subsection{Loophole in Parental and Child Involvement in ECE}

One of the most interactive approaches that have been used by early child educators is the Reggio Emilia which views early childhood education as a relationship among three protagonists: child, teacher and parent. Exchange and dialogue is valued between children, teachers and parents. Parents are important components in the curriculum implementation as active players in a child's learning experience. Although parents are not involved as direct consumers but, they are indispensable stakeholders. Studies in the Reggio Emilia approach show that parents form an essential resource in their child's learning. Moreover, many parents believe that their participation in children's education can help children do well at school (Grolnick et al., 1997). This is more so in developed countries who have more educated parents as our studies indicated. This is supported by Grolnick (1997), who reported that one of the predictors of parental involvement in children's education is the parent's educational level. Other substantial evidence also exists showing that children whose parents are involved in their schooling have significantly increased their academic achievement and cognitive development (Andrews et al., 1982; Henderson, 1981; and Herman \& Yeh, 1980). However, this study showed very little or no interaction exists between parent and parent and between child-child. Each parent(s) tends to be zealous to educate his or her child based on expectations, educational or cultural backgrounds. This being the first education which the child has learnt and is or may be reinforced daily forms the first foundation for further educational progress for each child in a school. However, there is no provision in many educational approaches where parents are encouraged to formally harmonize the kind of parallel curriculum which they bombard their children with. Hence, in this paper we highlight this loophole of parent-parent interaction which is essential in reducing such educational noise amongst learners. 


\subsection{The Emergent and Localized Workable Curriculum}

The whole interactive processes between parent-teacher-child differ in various cultures and educational backgrounds. Hence each interaction reacts to a particular global social and economic change and trend and modifies the educational policies and curriculum implementation processes so as to increase its efficacy. This leads to an emergent curriculum which tries to battle with the tides of change and maintains the educational goals and status of a particular third world country. This planning for an efficient emergent curriculum requires collaborative observation, documentation, creative brainstorming, flexibility and patience. Rather than starting with a lesson plan which requires a "hook" to get only the children interested, emergent curriculum might starts with the parental expectation and teachers' curriculum implementation, collaboration and end with a consideration of the children's interests (Jones et al., 2001).

\section{Conclusions and Suggestions}

This paper revealed that early childhood curriculum implementation in the third world countries is affected by different factors such as cultural differences, economic status and gaps between urban and rural stakeholders. These have been a challenge for many countries who are trying to inherit other global oriented approaches on teaching early childhood education. However, the incorporation of parent-parent and child-child interaction as facilitated by training teachers to collaborate with parents so as to help in minimizing these challenges and increases the efficacy of curriculum implementation. The maintenance of an interactive attitude can be important in establishing an emergent curriculum which is suitable for particular localities which have economic and cultural differences in a dynamic world. Moreover, there is necessity to consider all the stake holders as none of them would like to be outdated in a modern society. Hence, all cards must be placed on the table and considered in the educational game plan. Jiang and Deng (2008) had moreover argued that Chinese early childhood education programs did not have the "China taste" and hence they suggested that strategies of how to resolve practical problems in early child education institutes should consider various domestic socio cultural contexts before adopting educational foreign philosophies and curricula.

\section{References}

Birgen, P. (2008). East African Education Insight for quality Information, Education and Communications (p. $35)$.

Cheung, L., \& Wong, H. (2000). Academic Visit to Beijing: Report on the Exchange Meeting with Beijing Normal University.

Cotton, K., \& Green, K. (1988). Parent Involvement in Education. Portland, OR: Northwest Regional Educational Laboratory (draft).

Cresswell, J. W. (2003). Research Design: Qualitative, Quantitative, and Mixed Methods Approaches (2nd ed.). Thousand Oaks, CA: SAGE.

Doryan, A., Cautam, K. C., \& Foege, W. H. (2002). The Political Challenge: Commitment and Cooperation. In M. E. Young (Ed.), Investing in Our Children's Future: From Early Childhood Development to Human Development (pp. 375-391). Washington D. C.: The World Bank.

Edwards, C. P., \& Kutaka, T. S. (2015). Diverse Perspectives of Parents, Diverse Concepts of Parent Involvement and Participation: What Can They Suggest to Researchers? In S. M. Sheridan, \& E. M. Kim (Eds.), Foundational Aspects of Family-School Partnerships (Vol. 1). New York: Springer. http://dx.doi.org/10.1007/978-3-319-13838-1_3

Jiang, Y., \& Deng, S. (2008). The pledge of situation and the culture transition of early childhood education. Studies in Early Childhood Education, 160(4), 11-14.

Kingham, F. (2004). Interview with Ms Fiona Kingham, principal of Reggio-Kindergarten. Kuala Lumpur, Malaysia.

Kissassi, G. M. (1994). The Analysis of the Preschool Curriculum in Tanzania: Implications for a National Curriculum (Unpublished M.A. Dissertation). University of Dar es Salaam, Tanzania.

Li, H., \& Li, P. (2003). Lessons from implanting Reggio Emilia and Montessori curriculum in China (in Chinese). Preschool Education, 9, 4-5. 
Malaguzzi, L. A. (1996). Heresy of Light and Color. In Municipality of Reggio Emilia Infant-Toddler Centers and Preschools (Eds.), The Hundred Languages of Children: Narrative of the Possible. Reggio Emilia, Italy: Assessorato Scuole Infanzia Asili Nido.

Mtahabwa, L. (2001). Strategies for Promoting Family-Preschool Partnership in Tanzania: Focus on Holistic Preschool Education (Unpublished M.A. Dissertation). Faculty of Education, University of Dar es Salaam.

Mtahabwa, L. (2007). Pre-Primary Educational Policy and practice in Tanzania: Observation from Urban and Rural Pre-Primary Schools (PhD Thesis). Hong Kong University.

Nyland, B. (2003). The Formal Child-Care Centre as a Developmental Niche: A Longitudinal Study of Two Infants ( $\mathrm{PhD}$ thesis). Faculty of Learning and Education Development, University of Melbourne.

Ratelle, C. F., Guay, F., Larose, S., \& Senecal, C. (2004). Family correlates of trajectories of academic motivation during a school transition: A semiparametric group-based approach. Journal of Educational Psychology, 96, 743-754. http://dx.doi.org/10.1037/0022-0663.96.4.743

Ratelle, C. F., Larose, S., Guay, F., \& Senecal, C. (2005). Perceptions of parental involvement and support as predictors of college students' persistence in a science curriculum. Journal of Family Psychology, 19, 286-293. http://dx.doi.org/10.1037/0893-3200.19.2.286

Smith, S., Robbins, T., Stagman, S., \& Mathur, D. ( 2013). Parent Engagement from Preschool through Grade 3; A Guide for Policymakers Report. The National Center for Children in Poverty (NCCP), Mailman School of Public Health at Columbia University.

Tobin, J. (2007). An ethnographic perspective on quality in early childhood education. In J. Zhu (Ed.), Global perspectives on early childhood education (pp. 131-143). Shanghai: East China Normal University Press.

Xie, Q., \& Young, M. E. (1999). Intergrated Child Development in Rural China.

Zhu, J. X. (2009). Early Childhood Education and Relative Policies in China. International Journal of Child Care and Education Policy, 3(1), 51-60. http://dx.doi.org/10.1007/2288-6729-3-1-51

Zhu, J., \& Zhang, J. (2008). Contemporary trends and developments in early childhood education in China. International Journal of Early Years Education, 28(20), 173-182. http://dx.doi.org/10.1080/09575140802163584

Zhu, M. (2006). The development and reform of early childhood education in China: Practices and explorations in multi-sectoral cooperation in administrative systems. In M. Takeuchi (Ed.), New directions for early childhood education and care in the 21st century: International perspectives (pp. 33-65). Waverly, IA: G \& R Publishing Co.

\section{Copyrights}

Copyright for this article is retained by the author(s), with first publication rights granted to the journal.

This is an open-access article distributed under the terms and conditions of the Creative Commons Attribution license (http://creativecommons.org/licenses/by/3.0/). 